$\begin{array}{cc}\text { ACADEMIA ROMÂNĂ } & \text { Rev. Roum. Chim., } \\ \text { Revue Roumaine de Chimie } & \text { 2019.64(7), 561-567 } \\ \text { http://web.icf.ro/rrch/ } & \text { DOI: 10.33224/rrch.2019.64.7.02 }\end{array}$

\title{
INVESTIGATION OF SELECTIVE HYDROGENATION OF AROMATIC NITROCOMPOUNDS AND HYDROCARBONS
}

\author{
Larissa SASSYKOVA, ${ }^{*}$ Ulzhan OTZHAN and Anargul KURMANSITOVA \\ al-Farabi Kazakh National University, 71, al-Farabi, 050040 Almaty, Kazakhstan
}

Received August 8, 2017

\begin{abstract}
The liquid-phase hydrogenation of $\mathrm{NO}_{2}$-group in nitro compounds and hydrogenation of aromatic hydrocarbons (benzene, ethylbenzene, toluene) at the elevated pressure of hydrogen had been studied. In the work the high-active monoand bimetallic catalytic systems on various carriers were synthesized. The active phase of catalysts was based on platinum metals and copper. The optimum technological conditions of processes were determined. The mechanism of aromatic nitro compounds transformation was hydrogenation and identical for all used solvents. It was shown that monometallic $\mathrm{Rh} / \mathrm{Al}_{2} \mathrm{O}_{3}$ or bimetallic catalysts of $\mathrm{Rh}-\mathrm{Pt} / \mathrm{Al}_{2} \mathrm{O}_{3}$ compositions were the most effective catalysts for hydrogenation of aromatic hydrocarbons. The catalysts supported on aluminum oxide are more active and selective, than the catalysts on silica. GLC analysis and IR spectroscopy data showed the high yields of the target products (up to 98-99\%). Samples of the synthesized catalysts had been studied by a complex of physical and chemical research techniques.
\end{abstract}

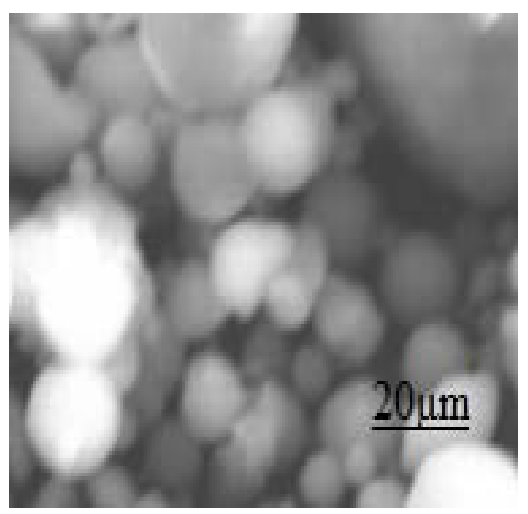

\section{INTRODUCTION}

Aromatic mono- and polyamines used in the synthetic dyes production for wools, clothes, furs and synthetic fibres are valuable products of organic chemistry and petrochemistry. ${ }^{1-6}$ Catalytic hydrogenation of nitro compounds in liquid phase for amines producing allows to perform the reactions at lower temperatures with considerable decrease in expenses of the electric power and potential of explosion of system. At solvents application during reaction the process proceeds in milder conditions, than during a steam method. Today in many countries, for example, in the territory of the CIS, the same method of nitrocompounds reduction to amines in solvents became one of the main methods of amines producing. ${ }^{7-10}$

Aromatic hydrocarbons hydrogenation processes are one of the important among large-tonnage processes of petrochemistry. ${ }^{11}$ For example from synthesizable benzene worldwide about $20 \%$ are applied further for cyclohexane producing.

Catalytic hydrogenation of aromatic hydrocarbons allows to change the chemical structure of hydrocarbons in the necessary direction and to provide high yields of main products, to improve quality of oil fuels, oils and raw materials for petrochemical processing. ${ }^{12-18}$

All processes of reduction of nitrocompounds and aromatic hydrocarbons are very difficult and multistage. In this case not only development of highactive, selective and stable catalysts, but also a careful selection of the process technological parameters (hydrogen pressure, solvent, temperature, mixing parameters and type of reactor) are required. So, the creation of selective catalysts for hydrogenation of aromatic nitrocompounds (on nitrogroup or a benzene ring) and aromatic hydrocarbons is a very important, perspective and an urgent issue.

\footnotetext{
*Corresponding author: larissa.rav@mail.ru
} 
The aim of the work was preparation of supported catalysts on the basis of platinum metals and researching their activity in the processes of hydrogenation of nitrocompounds (hydrogenation of nitrogroup) and aromatic hydrocarbons (benzene, ethylbenzene, toluene, cumene) at elevated hydrogen pressure.

\section{RESULTS AND DISCUSSION}

\section{Reduction of nitrogroup in aromatic nitrocompounds}

It was researched hydrogenation of nitrobenzene (NB), para-, ortho- nitrophenols (p-NP, o-NP).

At reduction of NB and NP on different samples of the catalyst with increasing the mass of the catalyst from 0.03 to $0.3 \mathrm{~g}$ the reduction rate increased by 7-8 times. Reduction of aromatic nitrocompounds has begun with selection of solvent. It was found for hydrogenation of NP that among the solvents used in this work (distilled water, $\mathrm{C}_{2}-\mathrm{C}_{5}$ alcohols) isopropanol is the most suitable for a process on Pd-catalyst, and ethanol on $\mathrm{Pd}-\mathrm{Pt}, \mathrm{Pd}-\mathrm{Cu}$ - catalysts. These solvents were also used further for studying the process of hydrogenation under various pressure and temperatures. The analysis during reaction showed that the mechanism of transformation of aromatic nitrocompounds is identical (hydrogenation) to all solvents. It was recorded that there were the least yields of arylamines when using distilled water and $\mathrm{C}_{4}-\mathrm{C}_{5}$ alcohols for reduction of nitrocompounds on Pd-Pt-catalysts. When using isopropanol for these catalysts the yield of target amines decreased due to the side reactions (reduction by a benzene ring). For example, when hydrogenation of $\mathrm{NB}$ in the final sample, except aniline, already at $20-25^{\circ} \mathrm{C}$ there was a cyclohexylamine- a product of hydrogenation of a benzene ring (4-6\%) and at further increase in temperature the content of cyclohexylamine increased to $8-10 \%$.

At hydrogenation of NB and NP on the Pdcontaining catalysts hydrogenation of only nitrogroups was noted, irrespective of solvents and the applied experimental conditions. Herewith the yield of aniline made $94-99 \%$, p-phenylenediamine 97-98\%, p-aminophenol - 89-97\% and o-aminophenol - 83-94\%.

At research of NP reduction in comparison with $\mathrm{NB}$ in identical experimental conditions the reduction rate of NP is slower, than NB reduction rate. The form of kinetic curves at change of a structure of aromatic nitro compound practically does not change. Herewith the reaction rate, the yield of aminophenol (AP) for p-NP is significantly higher, than in the case o-NP.

The studied nitro compounds on decrease in initial rate of hydrogenation on the synthesized catalysts form a row: NB $>$ p-NP $>0-N P$.

The appearance of $\mathrm{OH}$-group in a molecule of aromatic nitrocompound in $\mathrm{p}$ - and, especially, in oposition, reduces adsorption of nitro compound on the surface of the catalyst. Due to this, the ratio of reaction components (hydrogen and nitrocompounds) on the catalyst surface is broken, the reaction rate and yield of aminophenols (AP) are reduced. Relatively low speed of o-NP reduction, apparently, is associated with a manifestation of ortho-effect. $^{19,20}$ The ortho-effect is a set of all types of the spatial and stereoelectronic interactions of close located substituent and reaction center of a molecule. The substituent creates space barriers which prevent approaching of reagent to the reaction center and its solvating in solvent. Due to violation of coplanarity to an aromatic ring, the substituent or reactionary at ortho-arrangement there is a stereoelectronic braking of reaction. Ortho-substituents are close enough to the reaction center that considerable vicinal effect could occur.

p-aminophenol (p-AP) was added to the reaction medium in equivalent amount together with the p-NP for determination of the cause of reducing the velocity of hydrogenation. It was studied during the reaction that addition of the reaction product reduces the reduction rate and the amount of the absorbed hydrogen (table).

Possibly it is due to the blocking effect of the surface of the catalyst reaction product - p-AP.

Ratio $b_{1} / b_{2}$ indicates stronger adsorption of p-AP compared to p-NP. p-NP has fewer opportunities for access to the catalyst surface, as a surface of the catalyst in the first seconds of the reaction occupied by molecules of $\mathrm{p}-\mathrm{AP}$, which are readily adsorbed on the catalyst surface. The rate of the hydrogenation reaction of $\mathrm{p}-\mathrm{NP}$ is significantly reduced in the presence of p-AP due to the poisoning of the catalyst surface by the reaction product. The calculation of the rate constants based on adsorption coefficients shows that the reaction rate constant, confirming the assumption of zero orders the reduction of $\mathrm{p}-\mathrm{NP}$ on the substrate. 
Table 1

Reduction of p-NP, and p-NP (calculated on $400 \mathrm{~cm}^{3}$ of hydrogen) in the mixture with p-AP in an equivalent amount at $0.5 \mathrm{MPa}, \mathrm{T}=303 \mathrm{~K}$, catalyst-Pd- $\mathrm{Cu} / \gamma-\mathrm{Al}_{2} \mathrm{O}_{3}(0.05 \mathrm{~g})$

\begin{tabular}{|c|c|c|c|c|}
\hline \multirow[t]{2}{*}{ No } & \multirow{2}{*}{$\begin{array}{c}\text { The volume of hydrogen } \\
\text { absorbed from the gas } \\
\text { phase, } \mathrm{cm}^{3}\end{array}$} & \multicolumn{2}{|c|}{$\mathrm{W}, \mathrm{sm}^{3} / \mathrm{min}$. } & \multirow{2}{*}{$\begin{array}{c}\text { The ratio of the } \\
\text { adsorption coefficient } \\
b_{1 / b_{2}}\end{array}$} \\
\hline & & p-NP & $\mathbf{p}-\mathbf{N P}+\mathbf{p}-\mathbf{A P}$ & \\
\hline 1 & 100 & 85.0 & 20.0 & 0.23 \\
\hline 2 & 150 & 72.0 & 16.0 & 0.22 \\
\hline 3 & 180 & 65.0 & 13.5 & 0.21 \\
\hline 4 & 250 & 56.0 & 12.0 & 0.21 \\
\hline 5 & 300 & 34.0 & 7.7 & 0.22 \\
\hline
\end{tabular}

The data obtained in this work, suggests reduction mechanism of investigated nitrocompounds. At hydrogenation of $\mathrm{o}^{-}$and $\mathrm{p}-\mathrm{NP}$, apparently, at first is formed corresponding hydroxylamine derivative which is immediately rearranged into quinoneimine..$^{10}$ For this reason, it is difficult to register particle by gas-liquid chromatography. Then quinoid group quite easily rearranges to the corresponding aminophenol.

This reaction is substantially easier than the transformation of $\mathrm{NO}_{2}$-group into $\mathrm{NH}_{2}$-group.

\section{Hydrogenation of aromatic hydrocarbons}

In this work hydrogenation of benzene (B), ethylbenzene (EB), toluene $(\mathrm{T})$, cumene were studied.

The most active catalysts in the hydrogenation of aromatics were monometallic $\mathrm{Rh} / \mathrm{Al}_{2} \mathrm{O}_{3}$ (\% Rh$2-5 \%$ wt.) or bimetallic - Rh- $\mathrm{Pt} / \mathrm{Al}_{2} \mathrm{O}_{3}$ (atomic ratio of active metal - 3:7, 2:8, 1:9, total $\%$ - the content of metals: $1-5 \%$ ). It is not required an increase in temperature at hydrogenation of benzene in the absence of solvent; the process was carried out at 2.8-3.0 MPa. Hydrogenation of EB was carried out at heating the reaction system (not higher $50^{\circ} \mathrm{C}$ ), and at room temperature $-20-25^{\circ} \mathrm{C}$, with hydrogen pressures - 3.0-3.3 MPa.

The hydrogenation of cumene was carried out only at elevated temperatures (from 50 to $70-80^{\circ} \mathrm{C}$ ) and hydrogen pressure - 3.2-3.3 MPa.

The reaction rate and the catalyst activity decreases in the series of catalysts: Rh-Pt $>\mathrm{Rh}$ $\mathrm{Pd}>>\mathrm{Pd}-\mathrm{Ru}>\mathrm{Rh}$ (Fig. 1). Bimetallic catalysts are more active and selective than monometallic. The maximum values of benzene and toluene conversion (85.0-93.0\%) and yield of the corresponding hydrogenation products of the aromatic ring were found on the bimetallic catalysts $\mathrm{Pd}-\mathrm{Pt} / \mathrm{Al}_{2} \mathrm{O}_{3}$ and $\mathrm{Rh}-\mathrm{Pt} / \mathrm{Al}_{2} \mathrm{O}_{3}$. Catalysts on the carrier alumina were more active and selective than the catalysts on silica.

It was found that the reaction rate decreases with increasing complexity of the structure of compounds in the series: $\mathrm{B}>>\mathrm{EB}>$ cumene.

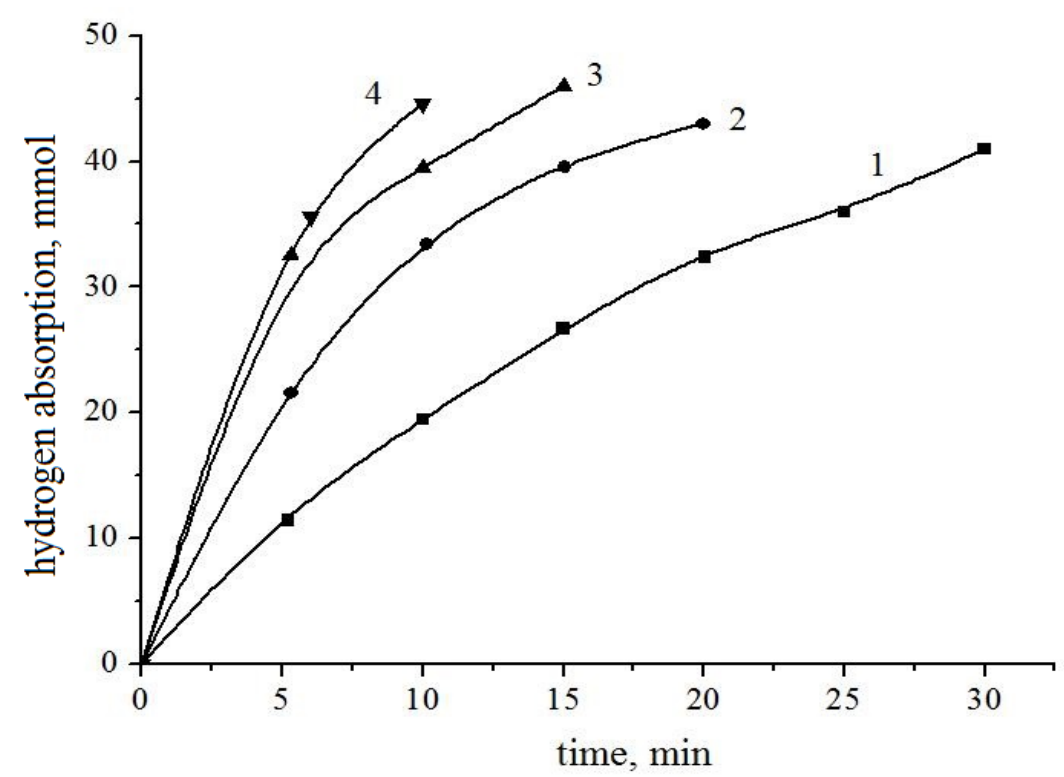

Fig. 1 - The hydrogenation of benzene in an autoclave without solvent at different catalysts supported on $\mathrm{Al}_{2} \mathrm{O}_{3}, \mathrm{P}_{\mathrm{H} 2}=2.5 \mathrm{MPa}, \mathrm{T}=120^{\circ} \mathrm{C}$ : 1-Rh, 2-Rh-Pd (1:1), 3-Rh-Pd(9:1), 4-Rh-Pt. 
These data are consistent with published data. For example, in $^{21-24}$ was shown that the rate of hydrogenation of $B$ is higher than the rate of its homologues hydrogenation. This is probably due to the presence of unsaturated side chains in aromatic hydrocarbons. GLC analysis and IR spectroscopy data showed the high yields of the target products (up to $98-99 \%$ ).

Hydrogenation of aromatic hydrocarbons on Pd-Pt-catalysts on various carriers was carried out. There is a partial reduction of benzene to cyclohexene (10-18\%) on Ru catalysts, the yield of cyclohexane - not higher than 30-46\%. Optimum catalysts for the hydrogenation of benzene and toluene - the catalysts with ratio $\mathrm{Pt}: \mathrm{Pd}=3-7 ; 2-8$; 1-9. Rh-Pt-catalysts supported on $\gamma-\mathrm{Al}_{2} \mathrm{O}_{3}$ are the most active catalysts in the process. The reaction rate and selectivity of the catalysts decreases in the series: $\mathrm{Rh}-\mathrm{Pt}>\mathrm{Rh}-\mathrm{Pd}>>\mathrm{Pd}-\mathrm{Ru}>\mathrm{Rh}$.

\section{Physico-chemical properties of the synthesized catalysts}

The used carriers and catalysts deposited on them were investigated by Electron Microscopy (TEM and SEM). Applying metals as mono-
$\mathrm{Pd} / \mathrm{Al}_{2} \mathrm{O}_{3}$ and $\mathrm{Rh} / \mathrm{Al}_{2} \mathrm{O}_{3}$ (Fig. 2b, d), and as bimetallic forms (Fig. 2c) produces a specific structure on the surface carrier.

It was established that structure of $\mathrm{Al}_{2} \mathrm{O}_{3}$ carrier consists of acicular crystalline structures. ${ }^{17}$ The dispersed particle size of $\sim 5.0 \mathrm{~nm}$ occupies the large swathes of the carrier surface. The average particle size in the $\mathrm{Pd} / \mathrm{Al}_{2} \mathrm{O}_{3}$ sample was approximately $1-3 \mathrm{~nm}$.

Hydrogen TPD data demonstrate (Fig. 3) that in the case of supported catalysts bimetallic number of forms of sorbed hydrogen, characteristic for each of the components remains constant, while the ratio between the hydrogen forms vary considerably with the change of the catalyst composition. Hydrogen from Pd-Pt-catalysts supported on $\gamma-\mathrm{Al}_{2} \mathrm{O}_{3}$ is desorbed in the form of dissolved and strongly adsorbed. It was observed a shift of position of peaks of a desorption of hydrogen and change in a ratio of a share of this or that form of hydrogen at addition of $\mathrm{Pd}$ and $\mathrm{Pt}$ in composition of the Rh-catalyst. Possibly, the high selectivity of $\mathrm{Rh}-\mathrm{Pt} \quad(9: 1) / \mathrm{Al}_{2} \mathrm{O}_{3}$ catalyst is associated with the presence of a large share of hydrogen with an average energy bond with the surface.

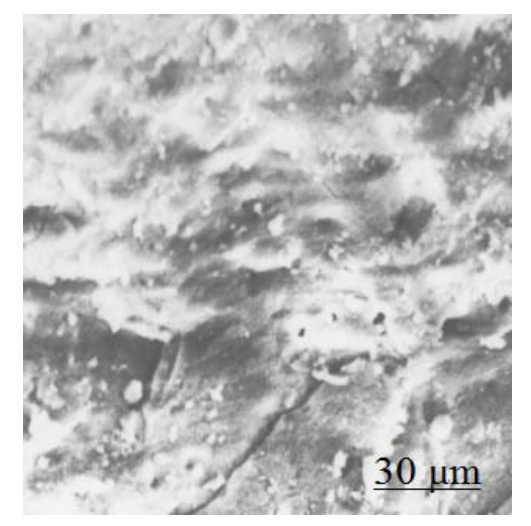

a

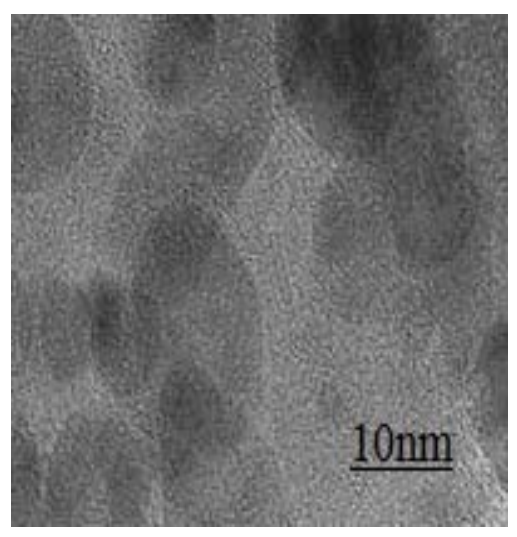

c

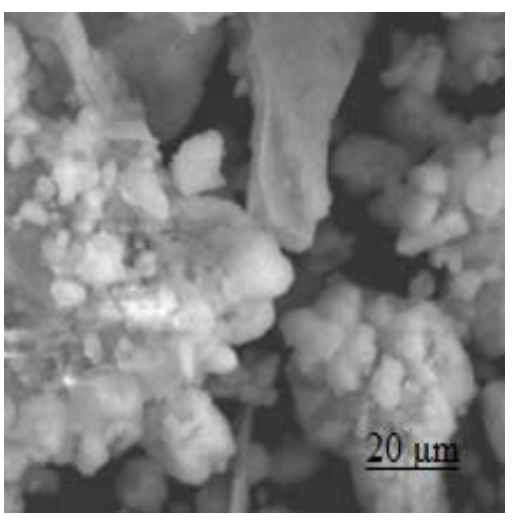

b

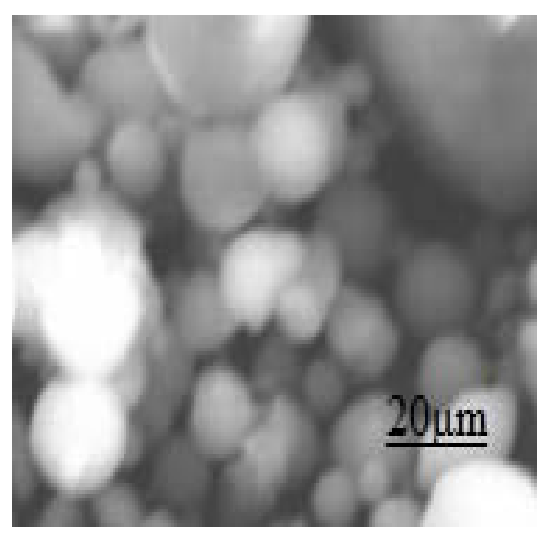

d

Fig. 2 - TEM and SEM-images: $\mathrm{a}-\mathrm{Al}_{2} \mathrm{O}_{3}, \mathrm{~b}-2 \% \mathrm{Pd} / \mathrm{Al}_{2} \mathrm{O}_{3}, \mathrm{c}-1 \% \mathrm{Pd}-\mathrm{Pt}(1: 1) / \mathrm{Al}_{2} \mathrm{O}_{3}, \mathrm{~d}-2 \% \mathrm{Rh} / \mathrm{Al}_{2} \mathrm{O}_{3}$. 


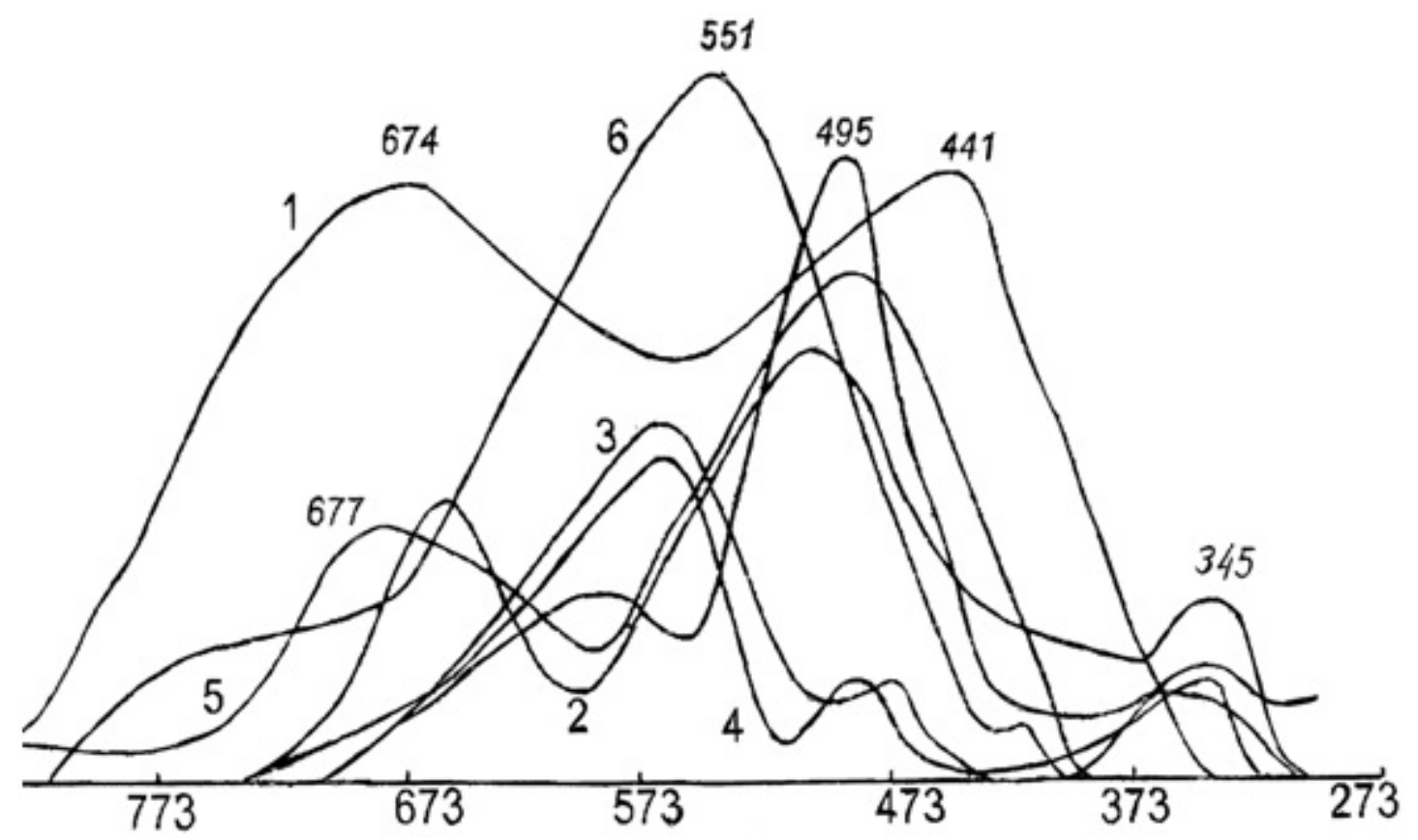

Fig. 3 - Thermal desorption of the catalysts with different compositions in condition of linear programmed increase of temperature of the used catalysts from 293 to $1023 \mathrm{~K}: 1-2 \% \mathrm{Rh} / \mathrm{Al}_{2} \mathrm{O}_{3} ; 2-2 \% \mathrm{Pd} / \mathrm{Al}_{2} \mathrm{O}_{3} ; 3-\mathrm{Rh}-\mathrm{Pd}(1: 1) / \mathrm{Al}_{2} \mathrm{O}_{3} ; 4-2 \% \mathrm{Rh}-\mathrm{Pt}(1: 1) / \mathrm{Al}_{2} \mathrm{O}_{3}$; 5-2\%Rh-Pd(9:1)/ $/ \mathrm{Al}_{2} \mathrm{O}_{3} ; 6-\operatorname{Rh}-\mathrm{Pt}(9: 1) / \mathrm{Al}_{2} \mathrm{O}_{3}$.

The results of the physico-chemical studies of the synthesized catalysts are consistent with the literature data. ${ }^{24-28}$

Microdiffraction patterns of catalyst with $\mathrm{Pd} / \mathrm{Al}_{2} \mathrm{O}_{3}$ composition corresponds to metallic $\mathrm{Pd}$, moreover, there are in a small amount (4-5\%) the particles of $\mathrm{PdO}$. X-ray phase analysis of the catalyst of composition $\mathrm{Pd} / \mathrm{Al}_{2} \mathrm{O}_{3}$ showed the presence of the metallic phase Pd peak - ICDD No.87-0653, $\mathrm{d}=2.25,1.95,1.38$, and phase $\gamma-\mathrm{Al}_{2} \mathrm{O}_{3}$ $(2 \mathrm{u}=458 \mathrm{~d}-1.99,2 \mathrm{u}=36.18 \mathrm{~d}-2.46){ }^{17,24-28}$ It was established the formation of solid solutions and the presence of traces of free Pd for systems Pd-Ptcatalyst. X-ray analysis of the reduced mixed Pd-Ptcatalysts showed that palladium indicated distinct midline intensity on the diffraction patterns; parameter of lattice didn't differ from the known in the literature. There are lines of Pd and unreduced oxide $\mathrm{PdO}$ on the diffractogramm, and its amount is close to $10 \%$. The results of temperatureprogrammed reduction (TPR) show that all Pdcontaining catalysts possibly contain palladium in at least in two forms: $\mathrm{PdO}$ particles and $\mathrm{Pd}$ oxide species stabilized on a surface.

For studying the behavior of NP at hydrogenation in the liquid phase at hydrogen pressure supported catalysts based on $\mathrm{Pd}$ and $\mathrm{Pt}$ with builder - $\mathrm{Cu}$ were synthesized. In the preparation of catalysts as the carriers were used $\gamma-\mathrm{Al}_{2} \mathrm{O}_{3}$ and activated carbon (C). It has been revealed that the size of $\mathrm{Pd}-\mathrm{Cu}$ nanoparticles deposited on $\gamma-\mathrm{Al}_{2} \mathrm{O}_{3}$ is approximately in the range of 5-12 nm. As a result of physico-chemical studies of catalysts it was found that catalysts supported on a surface area $\mathrm{C}$ is almost 2 times greater than the surface of catalysts supported on $\gamma-\mathrm{Al}_{2} \mathrm{O}_{3}$. Pores of catalysts with $\gamma-\mathrm{Al}_{2} \mathrm{O}_{3}$ carrier have the shape of cylinders, which radius are within the range 20-22 $\AA$. According to XPS, palladium on $\mathrm{C}$ is totally reduced to the zero-valent state, whereas $\gamma-\mathrm{Al}_{2} \mathrm{O}_{3}$, palladium is not fully reduced. Electron binding energy $\mathrm{Pd}^{\circ} 3 \mathrm{~d}_{5 / 2} \mathrm{Pd} / \mathrm{C}$ is $336.5 \mathrm{eV}$, corresponding to $\mathrm{Pd}^{2+}$. Modification of the catalyst with copper ions does not change the binding energy of the electron Pd $3 d_{5 / 2}$. By XRPmethod was revealed that in the copper-modified catalysts based on $\mathrm{Pd}(\mathrm{Pd}-\mathrm{Cu})-\mathrm{Pd}$ is in the zero valence state, and the state of copper $\mathrm{Cu}$ is characterized by the binding energy of $2 p_{3 / 2}$ electrons, equals to $932.7 \mathrm{eV}$, corresponding to $\mathrm{Cu}^{+}$. So it's possible to suggest that $\mathrm{Cu}$ catalysts are in the form of $\mathrm{Cu}_{2} \mathrm{O}$. It is found that in addition to the zero valent $\mathrm{Pd}$, there is also oxidized form of palladium $\left(\mathrm{PdO}_{2}\right)$ on the surface. ${ }^{17}$

\section{EXPERIMENTAL}

In the work the supported mono - and bimetallic catalysts on the basis of platinum metals had been prepared. Also 
catalysts on the basis of $\mathrm{Pd}$ and $\mathrm{Pt}$ with the modifying additive - $\mathrm{Cu}$ were used. The content of the active metals was varied within $0.5-5.0$ wt.\%. For synthesis of catalysts $\mathrm{PdCl}_{2}$ salts of "pure" brand and $\mathrm{RhCl}_{3} \cdot 3 \mathrm{H}_{2} \mathrm{O}, \mathrm{H}_{2} \mathrm{PtCl}_{6} \cdot 6 \mathrm{H}_{2} \mathrm{O}, \mathrm{RuOHCl}_{3}$, $\mathrm{CuSO}_{4} \cdot 5 \mathrm{H}_{2} \mathrm{O}$ salts of "chemically pure" brand were applied.

Chromatographically pure nitrobenzene (NB), para-, ortho- nitrophenols (p-NP, o-NP), benzene (B), ethylbenzene (EB), toluene $(\mathrm{T})$, cumene, which were prepared by vacuum distillation or a recrystallization, were used in performing this work. The physical and chemical properties of former to be hydrogenated compounds corresponded to references. ${ }^{29}$ Reactions were carried out as with solvents (distilled water, alcohols $\mathrm{C}_{2}-\mathrm{C}_{5}$ of "chemically pure" brand) as without solvents. Hydrogenation was studied with using of the electrolytic hydrogen from cylinder (99.8\%). For gas-liquid chromatography (GLC) helium from a cylinder (99.992\%) was used. For carrying out of the experiments on a liquidphase hydrogenation the kinetic installation of high pressure (KIHP) consisting of the advanced autoclave of Vishnevsky with intensive hashing and a measuring part was applied. ${ }^{30}$ The main part of KIHP (Fig. 4) is the advanced autoclave of Vishnevsky from a titanium of VT-3 (total amount - $60.0 \mathrm{ml}$ ) with the hermetic electric drive, turbine stirrer (rotation speed $-2,800 \mathrm{rev} . / \mathrm{min}$, stirring intensity $-40,000 \mathrm{Re}$ ).

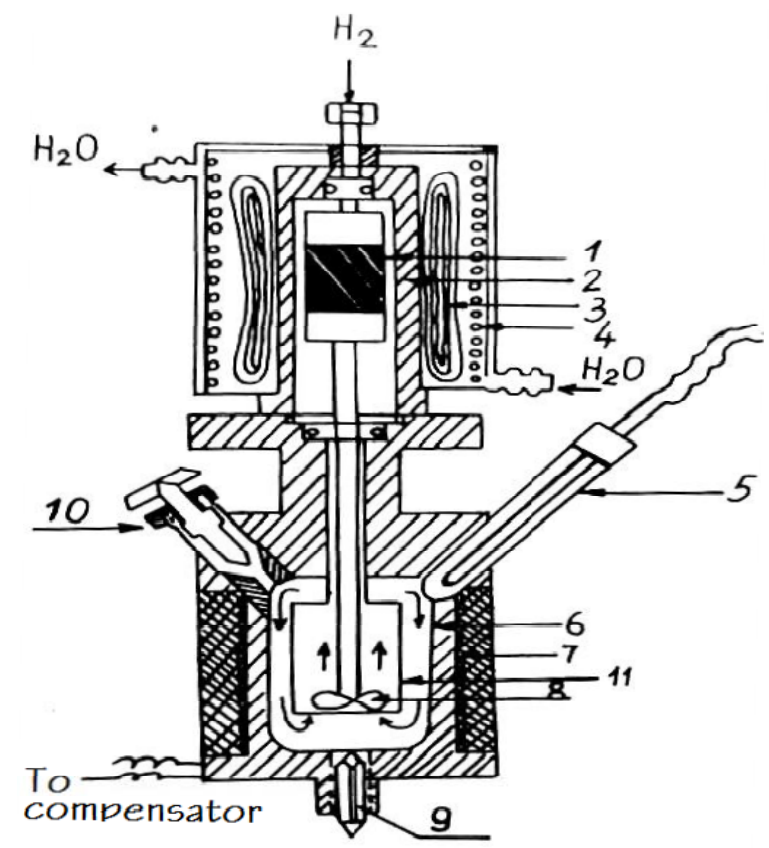

Fig. 4 - Scheme of the improved autoclave Vishnevsky with hermetic electric drive: 1 - rotor, 2 - a shielding sleeve, 3 - stator, 4 - cooling of the stator, 5 - thermocouple, 6 - reactor vessel, 7 - electrical heating, 8 - spiral mixer, 9 - lower cone valve, 10 - unit for enter the catalyst, the solvent and hydrogenated compounds, 11 - guiding glass.

The experiments were carried out in the isobaricisothermal mode by a method developed earlier in the laboratory. ${ }^{30-32}$ For the analysis of initial compounds and reaction products the methods of gas-liquid chromatography (GLC), diazometric titration and IR-analysis were used. ${ }^{31-33}$ In the work were also used physical and chemical research techniques of catalysts: X-ray diffraction, IR-analysis method on "Specord JR-75" and "UR-20". Samples of the synthesized catalysts are investigated by techniques of electron microscopy (scanning and penetration), porosimetry, BET (by nitrogen adsorption on the apparatus "Accusorb"), porosimetry. Assessment of accuracy of kinetic measurements was carried out by values of Kokhner's criterion. ${ }^{34}$

\section{Preparation of catalysts}

The catalysts for the hydrogenation of initial substances were synthesized by impregnating a carrier (alumina $\gamma-\mathrm{Al}_{2} \mathrm{O}_{3}$, silica-SiO ${ }_{2}$, activated carbon) with aqueous solutions of the active metal salts. Beforehand carriers were crushed to fractions 0.1 and 0.2 of $\mathrm{mm}$, washed out by distilled water at $80^{\circ} \mathrm{C}$ and dried at $100^{\circ} \mathrm{C}$. For carrying out a stage of impregnation was prepared aqueous $1.0 \%$ solution with the compound containing the active component. A solution of the active ingredient was added dropwise at a predetermined rate in a certain temperature regime under vigorous stirring.

Two-component catalysts (based on Pd-Pt, Rh-Pt, Pd-Rh) were prepared by joint impregnation of the carrier solutions of the corresponding compounds. After completion of the procedure catalysts leave to stand during the night before completion of impregnation of the carrier. Further, the catalyst mass was washed with distilled water from chlorine ions. The end of washing of the catalyst was checked on a qualitative test with $\mathrm{AgNO}_{3}$. Some samples of catalysts were reduced in hydrogen current at $200^{\circ} \mathrm{C}$ in the quartz furnace. If in the reduction time of the catalysts samples even slight quantities of $\mathrm{HCl}$ were noticed, the procedure of washing of the catalyst from $\mathrm{Cl}^{-1}$ ions was repeated. The prepared catalysts were cooled to room temperature and stored in sealed containers in desiccators. Before each experiment, the catalysts in the conditions required for the experiment, in a solvent medium was reduced in hydrogen for $30 \mathrm{~min}$.

\section{CONCLUSION}

The active selective catalysts on the basis of the platinum metals applied on various carriers were prepared and tested. The reactions of the liquidphase hydrogenation of the nitro group in nitro compounds and the hydrogenation of aromatic hydrocarbons (benzene, ethylbenzene, toluene) at different temperatures and hydrogen pressures were investigated. Probably the sharp decrease in the hydrogenation rate of aromatic nitrophenol, compared with nitrobenzene associated with decrease in the adsorption capacity of o- and p-NP, especially in the case of o-NP. It is obvious that the presence of groups OH-substituents in the molecule in the case of NP reduces the rate of hydrogenation of the compounds. Hydrogenation of aromatic hydrocarbons at elevated pressure of hydrogen was studied in the solvents and in the absence of solvents. Rh-Pt-catalysts supported on $\gamma-\mathrm{Al}_{2} \mathrm{O}_{3}$ are the most active catalysts in the process. The reaction rate and selectivity of the catalysts decreases in the series: Rh-Pt $>\mathrm{Rh}-\mathrm{Pd}>>\mathrm{Pd}-$ $\mathrm{Ru}>\mathrm{Rh}$. 


\section{REFERENCES}

1. I. I. Obraztsova, N. K.Eremenko and G. Y. Simenyuk, Solid Fuel Chem., 2012, 46, 364.

2. P. Sangeetha, K. Shanthi, K. S. Rama Rao, B. Viswanathan and P. Selvam, Appl.Catal,A, 2009, 353, 160.

3. E. A. Arnautova, T. S. Pivina, O. P. Gladkikh and L. V. Vilkov, J.Mol. Struct.: Theochem., 1996, 374, 137.

4. J. Winsiak and M. Klein, Ind. Eng. Chem. Prod. Res. Dev., 1984, 83, 44

5. G. Barone and D. Duca, J. Mol. Structure: Theochem., 2002, $584,211$.

6. H. J. Janssen, A. J. Kruithof, G. J. Steghuis and K. R. Westerterp, Ind. Eng. Chem. Res., 1990, $29,754$.

7. K. J. A. Raj, M. G. Prakash, R. Mahalakshmy, T. Elangovan and B. Vishwanathan, Chin. J. Cat., 2012, 33, 1299.

8. M. Turakova, T. Salmi, K. Eranen, J. Warna, D. Yu. Murzin and M. Kralik, Appl.Catal, A, 2015, 499, 66.

9. P. B. Kalantri and S. B. Chandalia, Ind. Eng. Chem. Process Des. Develop., 1982, 21, 186.

10. L. R. Sassykova, S. Sendilvelan, U. N. Otzhan, G. K. Vassilina, A. S. Zhumakanova, Z. T. Mataeva, M. B. Amangeldi and T. S. Abildin, News of the National Academy of sciences of the Republic of Kazakhstan, Series of Geology and Technical Sciences, 2018, 428, 18.

11. A. Corma, P. Concepción and P. Serna, Angewandte Chemie, 2007, 46, 7266.

12. X. Fan, A. A. Lapkin and P. K. Plucinski, Catalysis Today, 2009, 147, 313.

13. L. R. Sassykova, Y. A. Aubakirov, S. Sendilvelan, Zh. Kh. Tashmukhambetova, N. K. Zhakirova, M. F. Faizullaeva, A. A. Batyrbayeva, R. G. Ryskaliyeva, B. B. Tyussyupova and T. S. Abildin, Oriental J. Chem., 2019, 35, 22-38.

14. L. R. Sassykova, Chem. Biochem. Eng. Quarterly, 2017, 31, 447.

15. J. M. Orozco and G. Webb, J. Applied Catalysis, 1983, 1, 67.

16. D. Poondi and M. A.Vannice, J. Catalysis, 1996, 161, 742.
17. L. Sassykova and Y. Aubakirov, Chiang Mai J. Sci., 2018, 45,474

18. G. Mary, A. Esmaeili and J. Chaouki, Int. J. Chem. React. Eng, 2016, 14, 859.

19. J. P. Stradyn, "Polarography of organic nitrocompounds", Riga, Acad Latv.SSR, 1961, 68.

20. A. Remick. "Electronic submission in organic chemistry", M.:Inostr.liter., 1950, 320.

21. P. Tomkins, E. Gebauer-Henke, W. Leitner and Th. E. Muller, ACS Catal., 2015, 5, 203.

22. P. Kacer and L. Cerveny, Appl. Catal. A: General, 2002, 229, 193.

23. P. A. Kalmykov, N. A. Magdalinova and M. V. Klyuev, Pet. Chem., 2015, 55, 63.

24. R. J. Bertolacini, Nature, 1961, 92, 1179.

25. G. U. Huizi, X. U. Xiangsheng, C. Aoang and Y. Xinhuan, Chin. J. Cat., 2012, 33, 1423.

26. S. L. Karwa and R. A. Rajadhyaksha, Ind. Eng. Chem. Res., 1987, 26, 1746.

27. K. Taya, Sci. Papers. Inst. Phys. Chem. Res., 1962, 56, 285.

28. L. Pernoud, J. P.Candy, B. Didillon, R. Jacquot and J. M. Basset, Stud. Surface Sci. Cat., 2000, 130, 2057.

29. V. A. Rabinovich and Z. Ya. Havin, "Brief chemical reference book", L., Chemistry, 1978, 392.

30. Y. Aubakirov, L. Sassykova, S. Subramanian, K. Bhaskar, U. Otzhan, M. Amangeldi, T. Abildin, A. Zhumakanova, A. Zhussupova and M. Zharkyn, J. Chem. Tech. Metallurgy, 2019, 54, 522-530.

31. M. Tulepov, Z. Mansurov, L. Sassykova, D. Baiseitov, O. Dalelhanuly, Zh. Ualiev, Sh. Gabdrashova and Zh. Kudyarova, J. Chem. Techn. Metallurgy, 2019, 54, 531-538.

32. D. A. Baiseitov, M. I. Tulepov, L. R. Sassykova, Sh. E. Gabdrashova, A. N. Magazova, O. Dalelkhanuly, Zh. B. Kudyarova and Z. A. Mansurov, Bulg. Chem. Commun, 2017, 49, 600.

33. Guben-Veyl, "Methods of organic chemistry", V. 2, M., Khimiya, 1967.

34. N. V. Smirnov and I. V. Dunin-Barkovskii, "Course theory of probability and mathematical statistics for technical attachment", M.: Science, 1969. 
